\title{
The Role of Teacher Support, Students' Need Satisfaction, and Their Psychological Capital in Enhancing Students' Self-regulated Learning
}

\author{
Simona Lidia Sava ${ }^{1}$, Delia Vîrgă ${ }^{2}$, Ramona Palos ${ }^{2}$ \\ ${ }^{1}$ Department of Educational Sciences, West University of Timisoara, Romania \\ 2 Department of Psychology, West University of Timisoara, Romania
}

Because self-regulated learners do better in university and tend to be successful students, many authors consider that the development of self-regulatory learning skills in students has to become a priority for higher education. The present study aimed to investigate the explanatory role of psychological capital, as a personal resource, over and above teacher support and needs satisfaction, in relation to students' preference for self-regulating their learning (i.e., using cognitive strategies and self-regulation in academic learning). Data were collected from a convenience sample made up of 236 Romanian first-year students of psychology. Hierarchical multiple regressions indicated that psychological capital has an important role, over teacher support and the need for competence satisfaction, in the explanation of the students' preference for self-regulating their learning. From the practical perspective, research findings support educational practice interventions in enhancing self-regulation learning, because all three explored variables are changeable or malleable and can be fulfilled or improved through training.

Key words: teacher support, need satisfaction, psychological capital, self-regulated learning

\section{Introduction}

Self-regulation can be defined as self-generated thoughts, feelings, and actions in attaining important goals in life (Zimmerman, 1998, p. 73). In an academic environment, self-regulated students are seen as proactive learners who pursue their personal goals, use different learning strategies, and continually monitor their progress (Zimmerman, 1990). Because they do better at university (BakracevicVukman \& Licardo, 2010), and tend to be successful students (Andrzejewski, Davis,
Bruening, \& Poirier, 2016; Zusho, 2017), the development of their skills to self-regulate learning has to become a priority for higher education (Cassidy, 2011). Instruction teachers' behavior or learning environment can have a great impact on the way students self-regulate their learning (Boekarts \& Cascallar, 2006; Dignath \& Werf, 2012). On the other hand, students' commitment to engage in self-regulated learning is a voluntary act (Andrzejewski et al., 2016; Cleary \& Zimmerman, 2004). It is not enough for students to have self-regulated skills or an "enabling environment", they need to be motivated to involve themselves in self-

Correspondence concerning this article should be addressed to Ramona Palos, Department of Psychology, West University of Timisoara, 4 Vasile Pârvan Blvd., room 233, 300223 Timisoara, Romania. E-mail: ramona.palos@e-uvt.ro

ORCID https://orcid.org/0000-0002-4426-8178

Supplemental information for this article can be accessed at https://www.studiapsychologica.com/ index.php/view-articles/

Received April 16, 2019 
regulated learning (Cassidy, 2011; Pintrich \& de Groot, 1990). Therefore, we should consider at least the following two mutually dependent resources involved in fostering students' self-directed learning: social or contextual variables and personal variables (Pintrich, 2000).

In our study, the social or contextual variables with an impact on students' self-regulated learning refer to teacher support (e.g., help, guidance, feedback). The personal variables refer to students'psychologicalneeds (i.e., autonomy, competence, and relatedness), which can be satisfied in relation to other contextual variables (e.g., teacher support or learning environment), and to students' psychological capital. As a newly proposed construct, students' psychological capital represents a set of malleable personal resources consisting of self-efficacy, hope, optimism, and resilience (Carmona-Halty, Schaufeli, \& Salanova, 2019). It is considered a valuable individual resource for the effectiveness of learning, influencing students' readiness and desire to learn and to transfer learning (Combs, Luthans, \& Griffith, 2009).

Instructors can teach students how to regulate their learning by increasing the complexity of the study and learning strategies (Cleary \& Zimmerman, 2004), by encouraging them to control their learning process, or by adjusting their cognition and effort to the demands of the learning tasks (Pintrich \& de Groot, 1990). If teachers provide students with support, guidance or feedback, they will create an educational environment that can satisfy the students' psychological needs and increase their study engagement (Rahmadani, Schaufeli, Ivanova, \& Osin, 2019). Moreover, building highquality relationships with their students (i.e., satisfying their need for relatedness), teachers can help students to develop their psychological capital (i.e., a source of motivational energy, which may help students to strive for and achieve their goals - You, 2016), which, in turn, would develop their necessary skills and attitudes to meet academic requirements (Carmona-Halty et al., 2019). Psychological capital increases positive emotions (Probst, Gailey, Jiang, \& Bohle, 2017), and positive emotions enhance students' motivation and their use of learning strategies (You, 2016). Also, the development of students' psychological capital is significant for psychological needs satisfaction (Luthans \& Youssef, 2007; Verleysen, Lambrechts, \& Acker, 2015) which, in turn, can promote students' self-regulated learning (Liu et al., 2014).

There is some research emphasizing the influence of teacher support (Dignath, 2016; Zhu \& Mok, 2018), students' need satisfaction (Liu et al., 2014; Sierens, Vansteenkiste, Goossens, Soenens, \& Dochy, 2009) or psychological capital (You, Kim, \& Kang, 2014) on students' self-regulated learning separately, but little is known about these three variables taken together, especially how psychological capital can increase their impact. Consequently, the present study aimed to fill this gap by investigating the explanatory role of psychological capital, as a personal resource, over and above teacher support and needs satisfaction, in relation to students' preference for self-regulating their learning (i.e., using cognitive strategies and self-regulation in academic learning). Specifically, this research could provide valuable insights for practice by developing interventions focus on teachers and students training, because these three investigated variables are changeable or malleable, and can be improved (teachers support), satisfied/fulfilled (basic needs), or increased and developed (psychological capital).

\section{Self-Regulated Learning and Teacher Sup- port}

Self-regulated learning is considered to be an active process through which learners systematically use metacognitive, motivational, and behavioral strategies (Zimmerman, 1990; Zusho, 2017). From the classroom performance perspective, three components are considered essential: the cognitive strategies used in the learning process, the metacognitive strategies applied for planning, monitoring or changing learning, and effort management strategies practiced to work diligently and deal with difficult tasks (Pintrich, 2004). 
Metacognitive and effort management strategies were labeled as self-regulation, and along with cognitive strategies, are related to the cognitive component of self-regulated learning (Pintrich \& de Groot, 1990).

Because self-regulated learning is linked to or directly involved in academic performance (Rotgans \& Schmidt, 2009; Schloemer \& Brenan, 2006; Schunk, 2005), assisting students to become self-regulated learners is crucial. Teachers can foster self-regulated learning directly, by instructing students on how to learn and use learning strategies, and indirectly, by creating those learning environments which enable self-regulation (Dignath \& Werf, 2012; Dignath, 2016). They can provide students with explicit information about efficient practices and offer formative feedback on learning (Brown, Peterson, \& Yao, 2016; Zhu \& Mok, 2018). Received feedback is a valuable facilitator of self-regulated learning, especially when it is specific and formative, and students perceive it as being useful for their learning (Zhu \& Mok, 2018). Creating multiple curriculum opportunities and structuring the learning environment to allow students to practice and generalize cognitive and metacognitive strategies are also tactics to encourage students self-regulated learning (Lopez-Agudo \& Marcenaro-Gutierrez, 2017). It is not sufficient for teachers to develop a constructivist learning environment that enhances students' autonomy, they also need to teach them how to handle this autonomy in the learning process (Dignath \& Werf, 2012), and provide them with structure. Autonomy sustains students' engagement in self-regulated learning, while structure teaches them how to use self-regulatory strategies (Sierens et al., 2009). Active teaching methods that increase studentteacher and student-student interactions, as well as specific assessment practices, might influence students' self-regulated learning as well (Lopez-Agudo \& Marcenaro-Gutierrez, 2017; Rotgans \& Schmidt, 2009).

Based on the above arguments, we formulated the first hypothesis:

Hypothesis 1. Teacher support positively relates to students' cognitive strategies used in the learning process $(\mathrm{H} 1 \mathrm{a})$, and positively to students' self-regulation (use of metacognitive and effort management strategies) ( $\mathrm{H} 1 \mathrm{~b})$.

\section{Self-Regulated Learning and Need Satisfac- tion}

According to the Self-Determination Theory, autonomy, competence, and relatedness are the three psychological needs linked directly to a person's efficient functioning and wellbeing (Deci \& Ryan, 2000). The need for autonomy refers to students' desire to control their choices and to have psychological freedom when carrying out a learning task or an activity (van den Broeck, Vansteenkiste, De Witte, Soenens, \& Lens, 2010; DeHaan, Hirai, \& Ryan, 2016; Orkibi \& Ronen, 2017). The need for competence indicates the person's desire to experience efficacy and mastery in different educational situations (González-Cutre, Sicilia, Sierra, Ferriz, \& Hagger, 2016; Orkibi \& Ronen, 2017). The need for relatedness describes the students' desire to be connected with significant others and to be accepted as members of a group (van den Broeck et al., 2010; Orkibi \& Ronen, 2017).

When students' psychological needs are satisfied, they become highly intrinsically motivated and self-regulate more their learning (Sierens et al., 2009). When the learning environment supports autonomy by giving them freedom of control (Liu et al., 2014), supports competence by offering structure, and supports involvement through relatedness, engagement in self-regulated learning is highly probable (Grolnick \& Raftery-Helmer, 2015). Emphasizing educational activities based on interactions between students, which foster social relatedness, may influence their use of learning strategies and intrinsic motivation. Such contexts can facilitate students' engagement, deeper processing and learning, and enhance personal adjustment in classrooms and beyond (Deci, Ryan, \& Williams, 1996). Students' fulfillment of psychological needs shapes their academic performance, engagement, persistence, and effort invested in study activities (Gillet et al., 2019; Sulea, van Beek, Sârbescu, 
Vîrga, \& Schaufeli, 2015). This leads to the following hypothesis:

Hypothesis 2. Needs satisfaction positively relates to students' cognitive strategies used in the learning process $(\mathrm{H} 2 \mathrm{a})$, and positively to students' self-regulation (use of metacognitive and effort management strategies) $(\mathrm{H} 2 \mathrm{~b})$.

\section{Self-Regulated Learning and Psychological Capital}

Psychological capital (PsyCap) represents "one's positive appraisal of circumstances and probability for success based on motivated effort and perseverance" (Luthans, Avolio, Avey, \& Norman, 2007, p. 550). Four psychological resources are included in this construct: selfefficacy, hope, optimism, and resilience (Luthans, Avolio, et al., 2007). "Self-efficacy is linked to one's confidence to take on and put in the necessary effort to succeed in challenging tasks; hope refers to the perseverance towards goals or the redirection path to goals in order to succeed; optimism consists of making a positive attribution about succeeding now and in the future; and resilience relates to ones' ability, when faced with adversity, to sustain one's efforts to attain success" (Luthans, Youssef, \& Avolio, 2007, p. 3). Psychological capital is viewed as a core construct because the four psychological resources together have an impact more significant than the sum of their individual effects (Luthans, Avolio, et al., 2007; Luthans \& Avolio, 2014; Wernsing, 2014). Also, essential for practice is the idea that psychological capital can be developed and improved through training interventions (Dello Russo \& Stoykova, 2015; Luthans, Avolio, et al., 2007; Lupsa, Vîrgă, Maricutoiu, \& Rusu, 2019).

There are only a few studies carried out in the academic settings that explored the relationships of psychological capital with different variables, and most of them are linked to academic performance. For example, OrtegaMaldonado and Salanova (2017) investigated the relationships between undergraduate students' psychological capital, their coping strat- egies, satisfaction with university life, and academic performance. Siu, Bakker, and Jiang (2014) tested the relationship between psychological capital and study engagement, and how intrinsic motivation mediates these relationships. Other research emphasized the role of psychological capital on students' academic performance and showed how training increased the participants' level of psychological capital (Jafri, 2013; Luthans, Luthans, \& Jensen, 2012).

To our best knowledge, little attention has been paid to the impact of psychological capital on self-regulated learning and students' need satisfaction. Previous research found that students' psychological capital is significantly related to self-regulated learning and study engagement (You et al., 2014), and might influence learning motivation and learning transfer (Combs et al., 2009). You (2016) showed positive associations between psychological capital of college students and their learning empowerment (i.e., the feeling of competence to perform a task), and how this indirectly enhanced engagement. Also, previous investigations have shown that the satisfaction of needs for autonomy, competence, and relatedness could contribute to the development of psychological capital (Luthans \& Youssef, 2007). Carmona-Halty et al. (2019) emphasized that students' psychological capital can be enhanced if they have high-quality relationships with their teachers (i.e., their need for relatedness is satisfied). Teacher and peer support can increase academic engagement and students' hope (one of the psychological capital resources) as well (Orkibi \& Ronen, 2017). Conversely, Verleysen, Lambrechts, and Acker (2015) found that satisfying the need for competence influences all four psychological capital dimensions, while there was no direct impact on psychological capital by satisfying the needs for autonomy and relatedness. Based on the scarcity of information in this area, the aim of our study was to evaluate the added value that psychological capital has over teacher support and needs satisfaction in explaining students' cognitive strategies and their self-regulation used in the learning pro- 
cess. Consequently, we formulate the third hypothesis:

Hypothesis 3. Psychological capital positively relates to students' cognitive strategies used in the learning process $(\mathrm{H} 3 \mathrm{a})$, and positively to students' self-regulation ( $\mathrm{H} 3 \mathrm{~b})$, after controlling for the effect of teacher support and needs satisfaction.

\section{Methods}

\section{Participants and Procedures}

Data were obtained from a convenience sample made up of 236 Romanian first-year students of Psychology enrolled in Educational Psychology courses. The participants included 58 men $(24.6 \%)$ and 178 women $(75.4 \%)$, with an age range from 19 to 53 years $(M=21.18$, $S D=3.95)$. All the freshmen students were informed about the research (e.g., the aim, the conditions of the study, confidentiality of their responses), and anyone who wanted to participate in the research received a link to fill in four questionnaires online. The link was posted on the course communication group, and students needed about 30 minutes to fill in the questionnaires. From 324 students, only 236 replied $(72.83 \%$ response rate). The questionnaires were posted online in the last week of the first semester.

\section{Measures}

Three of the questionnaires were already validated on Romanian samples (i.e., PsyCap, needs satisfaction, and MSLQ), and the other one (i.e., teacher support) was used in previous studies. All the items and instructions were adapted to be relevant to the academic environment.

Self-regulated learning was assessed by using the second section of the Motivated Strategies for Learning Questionnaire (MSLQ Pintrich \& de Groot, 1990), considered the most commonly used instrument in self-regulated learning measurement (Panadero, 2017; Kokkinos \& Voulgaridou, 2018). This section consisted of two cognitive scales and mea- sured students' use of cognitive strategies and their self-regulation. Cazan (2011) investigated the convergent and predictive validity of the scales, after their translation into Romanian, and the findings showed that they are able to measure students' learning strategies in a reliable and valid manner. The use of cognitive strategies sub-scale was made up of 13 items, which focus on rehearsal (e.g., "When I study for a test I practice saying the important facts over and over to myself."), elaboration (e.g., "When I study for a test, I try to put together the information from class and the book.") and organizational strategies (e.g., "I outline the chapters in my book to help me study."). Cronbach's alpha for the sub-scale was .84 . The self-regulation sub-scale was made up of 9 metacognitive strategy items (e.g., "I ask myself questions to make sure I know the material I have been studying.") and effort management strategy items (e.g., "I work hard to get a good grade even when I don't like a class."). Cronbach's alpha for the sub-scale was .67, a value that can be considered acceptable (Sierens et al., 2009). All items were scored on a 7-point Likert scale $(1-$ not at all true of me, 7 - very true of me).

Teacher support was measured by using a scale from the Questionnaire on the Experience and Evaluation of Work (QEEW - van Veldhoven \& Meijman, 1994), which assesses support by direct supervisors. It is a 5 -items scale used in another Romanian research (Vîrgă, De Witte, \& Cifre, 2017) that had been adapted for educational context to assess teacher support. The extent to which an answer applies to students was scored on a 5point Likert scale (1 - never, 5 - always) (e.g., "Can you count on your teachers' support when you encounter difficulties?"). The internal consistency for the scale was .88 .

Students' need satisfaction was assessed with the Need Satisfaction at Work Scale (van den Broeck et al., 2010), adapted to the Romanian context by Tânculescu and Iliescu (2014) and showed good psychometric characteristics. Three subscales are included in the instrument: autonomy satisfaction (6 items; e.g., "I feel free to express my ideas and opin- 
ions at university."), competence satisfaction (6 items; e.g. "I feel competent as a student."), and relatedness satisfaction (6 items; e.g., "At university, I can talk to people about things that really matter to me."). Participants responded by using a 5 -point Likert scale ( 1 - totally disagree, 5 - totally agree). The Cronbach's alpha coefficient values range from .72 to .91. The questionnaire has been used previously in another study on Romanian students (Sulea et al., 2015).

Students' psychological capital was measured with a 24-item PsyCap Questionnaire (Luthans et al., 2007). The instrument was validated on the Romanian population with good psychometric characteristics (Lupsa \& Vîrgă, 2018). The questionnaire assesses four psychological resources: self-efficacy (6 items; e.g., "I feel confident analyzing a long-term problem to find a solution"), hope (6 items; e.g., "At present, I am energetically pursuing my study goals"), optimism (6 items; e.g., "I always look on the bright side of things regarding my studies") and resilience (6 items; e.g., "I usually manage difficulties one way or another at university"). Items were assessed using a 7-point Likert scale (1 - strongly disagree, 7 - strongly agree). Because empirical results have shown that overall psychological capital is a core construct (Luthans \& Avolio, 2014; Wernsing, 2014), the composite score was used. The internal consistency of the entire questionnaire in our sample was $\alpha=.91$.

\section{Data Analysis}

The means, standard deviations, internal consistency alphas, and Pearson correlation between all the study variables are presented in Table 1. All variables had normal distributions (Skewness and Kurtosis < 1). Thus, a general guideline for skewness and kurtosis is that numbers should be in between interval \pm 1 (Hair, Hult, Ringle, \& Sarstedt, 2017). Based on this guideline, the values of skewness and kurtosis for our variable are included in this range. Thus, the distributions are considered normal. The analyses were performed using IBM SPSS Statistics 23.0.
The study's hypotheses were tested by conducting two separately hierarchical regression analyses. The first considered the cognitive strategies component of self-regulated learning, and the second focused on the self-regulation component (metacognitive and effort management strategies) as criterion variables (Table 2). Teacher support, students' need satisfaction, and psychological capital were the predictor variables. Teacher support was included in the first step because it is considered a valuable social/contextual resource with an impact on the self-regulated learning process. Teachers can provide students with explicit information about efficient practices, can create multiple curriculum opportunities that encourage self-regulated learning, and can structure the learning environment to allow students to practice and generalize strategies (Paris \& Paris, 2001). Also, students' use of learning strategies might be influenced by the teaching methods and the assessment practices (Rotgans \& Schmidt, 2009). The other two variables (i.e., students' need satisfaction and psychological capital) included in the second and the third steps of the analysis are considered personal resources. Students' needs can be satisfied in relation to the learning environment. If this environment supports their autonomy, provides opportunities to acquire skills and fosters social relatedness there is an excellent chance for students to engage in self-regulated learning in the classroom (Liu et al., 2014). Psychological capital, as a source of motivational energy, was included in the third step of the regression to investigate the explanatory role of this malleable resource, over and above teacher support and needs satisfaction, in relation to cognitive strategies and self-regulation in academic learning.

\section{Results}

Table 1 presents the correlation matrix between study variables. All predictors (i.e., teacher support, students' need satisfaction, and psychological capital) showed positive and significant correlations with each of the dependent variables, respectively, the stu- 
dents' cognitive strategies and their self-regulation.

The first hypothesis of the study - Teacher support positively relates to students' cognitive strategies used in the learning process ( $\mathrm{H} 1 \mathrm{a})$, and positively to students' self-regulation (use of metacognitive and effort management strategies) $(\mathrm{H} 1 \mathrm{~b})$ - received statistical support as follows (Table 1). Significant positive associations were found between teacher support and the use of cognitive strategies $(r=$ $.34, p<.001 ; \mathrm{H} 1 \mathrm{a}$ ), and between teacher support and students' self-regulation $(r=.40, p<$ $.001 ; \mathrm{H} 1 \mathrm{~b})$.

The second hypothesis - Needs satisfaction positively relates to students' cognitive strategies used in the learning process (need for autonomy: $r=.16, p<.01$; need for competence: $r=.34, p<.001$; need for relatedness: $r=.14, p<.05 ; \mathrm{H} 2 \mathrm{a}$ ), and positively to students' self-regulation (use of metacognitive and effort management strategies) (need for autonomy: $r=.28, p<.001$; need for competence: $r=.46, p<.001$; need for relatedness: $r=.20, p<.001 ; \mathrm{H} 2 \mathrm{~b})$ - also received statistical support (Table 1). Thus, all three psychological needs (i.e., autonomy, competence, and relatedness) correlated positively and significantly with students' cognitive strategies $(\mathrm{H} 2 \mathrm{a})$, and self-regulation $(\mathrm{H} 2 \mathrm{~b})$.

Psychological capital correlated positively and significantly with cognitive strategies $(r=$ $.61, p<.001)$ and with self-regulation $(r=.51$, $\mathrm{p}<.001)$.

The results of hierarchical regression analysis with the two dependent variables (i.e., cog- nitive strategies and self-regulation) are presented in Table 2. Regarding the use of cognitive strategies as the criterion measure, in the first step, teacher support accounted for $11.4 \%$ of the variance $\left(R^{2}=.114\right)$, and the model of regression was significant $[F(1,234)=30.23$, $p<0.001$ ]. By adding in the second step of the regression model, the need for autonomy, competence and relatedness, and controlling the influence of teacher support, the predictive value of the second model (also significant $[F(3,231)=4.54, p<0.001]$,$) increased to$ $16.4 \%\left(\Delta R^{2}=.049\right)$; specifically, the need for competence added significant variance $(\beta=$ $.26, p<0.001)$. In the third step, the psychological capital was related to the use of cognitive strategies $(\beta=.63 ; p<0.001)$ and explained $23.5 \%$ of additional variance $\left[\Delta R^{2}=.235\right.$; $F(1,230)=89.96, p<0.001]$, after controlling the influence of the students' need and teacher support. The final model, which includes all five predictors, explained students' use of cognitive strategies in the learning process at a rate of $39.9 \%\left(R^{2}=.399\right)$.

Also, Table 2 shows that for students' preference for engaging in self-regulation as the criterion measure, teacher support at Step 1 accounted for $15.7 \%$ of the variance $(\beta=.39$; $p<0.001)$, and the first model of the regression was significant $[F(1,234)=43.45, p<$ 0.001]. In Step 2, students' needs accounted for an additional $10.3 \%$ of the variance $\left(\Delta R^{2}=103\right)$, after controlling the influence of teacher support, the second model being also significant $[F(3,231)=10.72, p<0.001]$; specifically, the need for competence added sig-

Table 1 Correlation matrix between study variables

\begin{tabular}{lrrlllllll}
\hline Variables & \multicolumn{1}{c}{ M } & \multicolumn{1}{c}{$S D$} & 1 & 2 & 3 & 4 & 5 & 6 & 7 \\
\hline 1. Cognitive Strategies & 66.72 & 11.88 & $(.84)$ & & & & & & \\
2. Self-regulation & 41.69 & 7.34 & $.66^{* *}$ & $(.67)$ & & & & & \\
3. Teacher support & 18.96 & 4.13 & $.34^{* *}$ & $.40^{* *}$ & $(.88)$ & & & & \\
4. Need for Autonomy & 20.11 & 4.52 & $.16^{*}$ & $.28^{*}$ & $.48^{* *}$ & $(.72)$ & & & \\
5. Need for Competence & 23.94 & 5.36 & $.34^{* *}$ & $.46^{* *}$ & $.44^{* *}$ & $.45^{* *}$ & $(.91)$ & & \\
6. Need for Relatedness & 21.30 & 5.65 & $.14^{*}$ & $.20^{* *}$ & $.39^{* *}$ & $.38^{* *}$ & $.28^{* *}$ & $(.86)$ & \\
7. PsyCap & 4.59 & .95 & $.61^{* *}$ & $.51^{* *}$ & $.45^{* *}$ & $.43^{* *}$ & $.61^{* *}$ & $.24^{* *}$ & $(.91)$ \\
\hline
\end{tabular}

Note. $N=236 ;{ }^{* *} p<0.01 ;{ }^{*} p<0.05$; Self-regulated learning: cognitive strategies and self-regulation dimensions; Students' need satisfaction: need for autonomy satisfaction, need for competence satisfaction, need for relatedness satisfaction; Students' psychological capital = PsyCap; Values of the internal consistency alphas are displayed in italic in the diagonal. 
Table 2 Hierarchical regression analysis predicting the two components of self-regulated learning (i.e., cognitive strategies and self-regulation components)

\begin{tabular}{|c|c|c|c|c|c|c|}
\hline \multirow[t]{3}{*}{ Variables } & \multicolumn{6}{|c|}{ Self-regulated learning } \\
\hline & \multicolumn{3}{|c|}{ Cognitive strategies } & \multicolumn{3}{|c|}{ Self-regulation } \\
\hline & $R^{2}$ & $\Delta R^{2}$ & $\beta$ & $R^{2}$ & $\Delta R^{2}$ & $\beta$ \\
\hline Step 1 & .114 & $.114^{\star *}$ & & .157 & $.157^{* *}$ & \\
\hline Teacher support & & & $.33^{* *}$ & & & $.39^{* *}$ \\
\hline Step 2 & .164 & $.049^{* *}$ & & $.260^{* *}$ & $.103^{* *}$ & \\
\hline Teacher support & & & $.26^{* *}$ & & & $.23^{* *}$ \\
\hline Need for autonomy & & & -.08 & & & .00 \\
\hline Need for competence & & & $.26^{\star *}$ & & & $.35^{\star *}$ \\
\hline Need for relatedness & & & -.01 & & & .00 \\
\hline Step 3 & .399 & $.235^{\star *}$ & & $.319^{* *}$ & $.059^{* *}$ & \\
\hline Teacher support & & & $.15^{*}$ & & & $.17^{* *}$ \\
\hline Need for autonomy & & & $-.16^{* *}$ & & & -.04 \\
\hline Need for competence & & & -.04 & & & $.20^{* *}$ \\
\hline Need for relatedness & & & -.00 & & & .01 \\
\hline PsyCap & & & $.63^{* *}$ & & & $.31^{* *}$ \\
\hline
\end{tabular}

Note. $N=236 ;{ }^{* *} p<0.01 ;{ }^{*} p<0.05$; Self-regulated learning: cognitive strategies dimension and self-regulation dimension; Students' need satisfaction: need for autonomy, competence and relatedness satisfaction; Students' psychological capital = PsyCap.

nificant variance $(\beta=.35, p<0.001)$. In the third step, students' psychological capital was related to self-regulation $(\beta=.31 ; p<0.001)$ and explained $5.9 \%$ of additional variance $\left[\Delta R^{2}=.059 ; F(1,230)=19.86, p<0.001\right]$, after controlling the influence of students' needs and teacher support. The final model that includes all five predictors explained students' selfregulation of the learning process at a rate of $31.9 \%\left(R^{2}=.319\right)$.

Altogether, the results of all the regression analyses supported Hypothesis 3, which stated that psychological capital positively relates to students' cognitive strategies used in the learning process $(\mathrm{H} 3 \mathrm{a})$, and positively to students' self-regulation ( $\mathrm{H} 3 \mathrm{~b})$, after controlling for the effect of teacher support and needs satisfaction.

\section{Discussion}

The current study aimed to investigate the explanatory role of psychological capital, as a personal resource, over and above teacher support and needs satisfaction, in relation to students' preference for self-regulating their learning (i.e., using cognitive strategies and self-regulation in academic learning). The results indicated that psychological capital, as a personal resource, plays an essential role, after controlling for teacher support and needs satisfaction, in the explanation of the students' preference for using cognitive strategies and self-regulation in academic learning. In other words, students who got more support from their teachers in the learning process, who felt that their need for competence was satisfied during instruction, and who had a high level of psychological capital, reported a higher preference for the use of cognitive and metacognitive strategies, and self-regulating their effort.

The results of the study confirmed the first hypothesis. Teacher support was positively related to students' use of cognitive, metacognitive, and effort management strategies, and it was identified as a predictor of students' selfregulated learning. This is following other studies that emphasized the influence of teacher support (Dignath, 2016; Paris \& Paris, 2001). Students who ask for, receive and use teachers' support about how to link learning strate- 
gies with desired outcomes, or about relationships between cues and successive states of achievement, are more successful in selfregulating their learning (Brown et al., 2016).

The results of the study confirmed the second hypothesis as well. Needs satisfaction positively related to students' cognitive strategies and their self-regulation in the learning process. Despite these relationships, only the need for competence, the satisfaction of which is considered to stimulate people functioning and well-being on a more general level (van den Broeck, Vansteenkiste, de Witte, \& Lens, 2008), was found as a significant predictor for self-regulated learning. Surprisingly, the need for autonomy negatively predicted the use of cognitive strategies, which is slightly different from other research. For example, Young (2005) pointed out that students who perceive themselves as being autonomous and competent tend to be intrinsically motivated. They know how to adjust their learning strategies to the content and requirements of the tasks, what kind of cognitive and metacognitive strategies they need to solve them, and how to manage their effort strategies. Also, that feeling of competence needs to be accompanied by feelings of autonomy for individuals to be self-regulated (Deci et al., 1996; Valero-Valenzuela \& Manzano-Sánchez, 2019). The need for competence is reflected in students' understanding of how to self-regulate their learning, whereas the need for autonomy is reflected in the students' willingness to get involved in study activities (Grolnick \& Raftery-Helmer, 2015). A possible explanation for our result could be linked to the reduced academic experience of the students. They were in the first year, and many of them did not know how to study, what to learn, or how to organize their work. Maybe, at this stage, they needed more structure and rules, with clear expectations regarding their behavior, and more help in engaging in learning tasks. Autonomy is linked to students' independence and their opportunity to make choices (e.g., learning strategies, effort, and persistence in academic tasks), but they might also experience autonomy satisfaction when they follow teachers' requests, rules or suggestions, and can act of their own free will if teachers give them rational motives why it is better to do so (van den Broeck et al., 2010). Teacher support (e.g., guidance, constructive feedback), can help students to increase confidence in monitoring their study behavior, and nurture their need for competence, namely the "know-how" of self-regulated learning. When the students become confident, they can develop the willingness (autonomy) to initiate self-regulated learning (Sierens et al., 2009).

Another meaningful result that confirmed the third hypothesis is the significant value added by psychological capital in explaining students' preference for cognitive, metacognitive, and use of effort management strategies. It has already been shown that psychological capital is a valuable resource for learning motivation (Combs et al., 2009) or learning empowerment (You, 2016), but few studies have approached psychological capital as a core construct in relation to self-regulated learning in educational settings (You, 2016). The level of psychological capital influences students' preferences for or engagement in self-regulated learning (You, 2016). Specifically, if students are generally more positive, confident, and flexible in the change process, they are willing to expend additional energy and effort to pursue their learning goals by using cognitive and metacognitive strategies (You, 2016). In the current study, students' psychological capital was positively related to their use of cognitive, metacognitive and effort management strategies, and it was also a predictor for both dimensions of self-regulated learning (i.e., cognitive strategies use and self-regulation). This means that students' psychological capital can have an essential role in cognitive strategies use and students' self-regulation of learning, if they get teacher support and have an environment that assures the satisfaction of their competence needs. What could be interesting about our results is that psychological capital had a higher impact on students' use of cognitive strategies than it had on their use of metacognitive and effort management strategies (the explained variance was more signifi- 
cant in the first case, $\Delta R^{2}=.253$ ). Cognitive strategies can be taught and learned through training, and then can be applied in learning situations (Dignath \& van der Werf, 2012). However, self-regulation is more complex, and its quality depends on motivation (whether or how much to study), method (how to study), and time (how much time is spent studying and how effectively this time is spent) and is viewed as "a context-specific process that is selectively used to succeed in school" (Zimmerman, 1998, p. 73). In other words, it is not enough for students to have strategies, they need to be motivated to use the strategies in the learning process. The limited academic experience of our students in dealing with different courses and teachers, diverse styles and demands, and their insufficient time to adapt to the academic context and requirements (e.g., to know how to learn or how to manage tasks) (Gillet et al., 2019) could explain this result. Accordingly, further studies are necessary to determine if and how these variables are reflected in self-regulated learning. For example, based on these findings, a model could be tested, which would explore if psychological capital (as a core construct, but also with each of its resources - self-efficacy, hope, optimism, resilience) mediates the relationships between social or contextual variables (i.e., teacher support) and each learning strategy that students can use in their academic learning. Knowing this, training interventions could be designed for both teachers and students.

Some limitations of this research need to be acknowledged. First of all, the results were based on self-report questionnaires, and students' answers can have a high level of social desirability. Second, the sample could be considered not well balanced regarding the number of men and women. In this case, further investigation is needed to see if there are differences in the way that students regulate their learning and use their personal and contextual resources. Also, the findings should be considered with caution because our participants were only from the Psychology specialization. Thus, more research would be useful to analyze whether and how learning behavior could be shaped by the students' specialty. Another limit is given by the Breusch-Pagan test, which was significant for cognitive strategies. This violation of homoscedasticity could lead to bias in the error terms and distortion of significance for the model which predicts cognitive strategies of students. In future research, it would be useful to test a new model with other predictors, like academic engagement or study demands and resources (Klein, Gerhard, Büchner, Diestel, \& SchermellehEngel, 2016). Despite the limitations, these findings may well be significant for educational practice.

Helping students to become self-regulated learners means assisting them in acquiring necessary skills and structuring the environment to facilitate practice and engagement in self-regulated learning (Cleary \& Zimmerman, 2004; Paris \& Paris, 2001). That is, students need "skill" and "will" to self-regulate learning (Liu et al., 2014). The results of the present study showed that psychological capital, as a personal resource of motivational energy (support for "will"), has an incremental value over and above teacher support (support for "skill"), and need for competence satisfaction (support for "will") in explaining students' preference to self-regulate their learning. From the theoretical perspective, our findings help to enrich the understanding of the impact of psychological capital on self-regulated learning, a construct that has not been explored enough in the educational context. From a practical perspective, these results are essential because all three variables are malleable and can be enhanced through appropriate training. Thus, educational institutions (e.g., schools, universities) could find ways to make teachers more aware of the difference they can make to their students by helping them to selfregulate learning. They can design formal training for teachers of how to aid students to regulate their learning, and also how to find successful ways of integrating practices of selfregulated learning into their teaching (Dignath \& Werf, 2012). For students, they may also run formal training to explain the conceptual mean- 
ing of self-regulated learning, its relationship with academic achievement (Zusho, 2017), and those personal and contextual factors which can help them to achieve highly efficient self-regulated learning (Zhu \& Mok, 2018). Also, institutions can organize intervention programs for both teachers and students to develop their psychological capital (CarmonaHalty et al., 2019; Luthans et al., 2012). Previous research showed improvement in psychological capital after specific training and emphasized its visible, long-term effects (Dello Russo \& Stoykova, 2015). Beyond the organizational level, namely what institutions can do to improve students' self-regulated learning, at the individual level teachers can structure the learning environment to facilitate the satisfaction of students' psychological needs by encouraging self-initiative, by offering feedback or by creating opportunities for social interactions (Deci et al., 1996; DeHaan et al., 2016; Orkibi \& Ronen, 2017). Any improvement in each of these three variables can influence students' engagement in self-regulated learning.

In conclusion, the most critical finding of our research is related to the role of psychological capital in explaining the students' preference for self-regulated learning after they get teacher support and their needs for competence are satisfied. Therefore, it may be suggested that motivational variables, such as psychological capital and needs satisfaction, could act as the "will" which may determine students to use their "skills" (i.e., cognitive, metacognitive and effort management strategies) in the learning process.

\section{References}

Andrzejewski, C. E., Davis, H. A., Bruening, P. S., \& Poirier, R. R. (2016). Can a self-regulated strategy intervention close the achievement gap? Exploring a classroom-based intervention in $9^{\text {th }}$-grade earth science. Learning and Individual Differences, 49, 85-99. doi.org/10.1016/j.lindif. 2016.05.013

Bakracevic-Vukman, K., \& Licardo, M. (2010). How cognitive, metacognitive, motivational, and emotional self-regulation influence school performance in adolescence and early adulthood. Educational Studies, 36(3), 259-268. doi: 10.1080/ 03055690903180376

Boekaerts, M., \& Cascallar, E. (2006). How far have we moved toward the integration of theory and practice in self-regulation? Educational Psychology Review, 18, 199-210. doi: 10.1007/s10648006-9013-4

Breslin, R. W. (1970). Back-translation for crosscultural research. Journal of Cross-Cultural Psychology, 1, 185-216.

Brown, G. T. L., Peterson, E. R. P., \& Yao, E. S. (2016). Student conceptions of feedback: Impact on self-regulation, self-efficacy, and academic achievement. British Journal of Educational Psychology, 86, 606-629. doi: 10.1111/bjep.12126

Carmona-Halty, M., Schaufeli, W. B., \& Salanova, M. (2019). Good relationships, good performance: The mediating role of Psychological Capital - a three-wave study among students. Frontiers in Psychology, 10(306), 1-5. doi: 10.3389/fpsyg. 2019.00306

Cassidy, S. (2011). Self-regulated learning in higher education: Identifying key component processes. Studies in Higher Education, 36, 989-1000. doi: 10.1080/03075079.2010.503269

Cazan, A-M. (2011). Psychometric properties of cognitive self-regulation MSLQ scales. Romanian Journal of Experimental Applied Psychology, 2(1), 49-57.

Cleary, T., \& Zimmerman, B. J. (2004). Self-regulation empowerment program: A school-based program to enhance self-regulated and self-motivated cycles of student learning. Psychology in the Schools, 41(5), 537-550. doi: 10.1002/pits. 10177

Combs, G., Luthans, F., \& Griffith, J. (2009). Learning motivation and transfer of human capital development: Implications from psychological capital. In R. J. Burke \& C. L. Cooper (Eds.), The Peak Performing Organization (pp. 73-91). London \& New York: Routledge/Taylor \& Francis.

Deci, E. L., Ryan, R. M., \& Williams, G. C. (1996). Need satisfaction and the self-regulation of learning. Learning and Individual Differences, 8, 165-183.

Deci, E. L., \& Ryan, R. M. (2000). The "What" and "Why" of goal pursuits: Human needs and the selfdetermination of behavior. Psychological Inquiry, 11(4), 227-268.

DeHaan, C. R., Hirai, T., \& Ryan, R. M. (2016). Nussbaum's capabilities and self-determination theory's basic psychological needs: Relating some fundamentals of human wellness. Journal of Happiness Studies, 17, 2037-2049. doi: 10.1007/ s10902-015-9684-y 
Dello Russo, S., \& Stoykova, P. (2015). Psychological Capital Intervention (PCI): A replication and extension. Human Resource Development Quarterly, 26(3), 329-347. doi: 10.1002/hrdq.21212

Dignath-van Ewijk, C., \& van der Werf, G. (2012). What teachers think about self-regulated learning: Investigating teacher beliefs and teacher behavior of enhancing students' self-regulation. Education Research International, 1-10. Hindawi Publishing Corporation. doi: 10.1155/2012/741713

Dignath-van Ewijk, C. (2016). Which components of teacher competence determine whether teachers enhance self-regulated learning? Predicting teachers' self-reported promotion of self-regulated learning by means of teacher beliefs, knowledge, and self-efficacy. Frontline Learning $R e-$ search, 4(5), 83-105. doi.org/10.14786/fIr.v4i5. 247

Gillet, N., Morin, A. J. S., Huyghebaert, T., Burger, L., Maillot, A., Poulin, A., \& Tricard, E. (2019). University students' need satisfaction trajectories: A growth mixture analysis. Learning and Instruction, 60, 275-285. doi: 10.1016/j.learninstruc. 2017.11.003

González-Cutre, D., Sicilia, A., Sierra, A. C., Ferriz, R., \& Hagger, M. S. (2016). Understanding the need for novelty from the perspective of self-determination theory. Personality and Individual Differences, 102, 159-169. doi: 10.1016/j.paid 2016.06.036

Grolnick, W. S., \& Raftery-Helmer, J. N. (2015). Context supporting self-regulated learning at schoo transitions. In T. J. Cleary (Ed.), Self-regulated learning interventions with at-risk youth: Enhancing adaptability, performance, and well-being ( $\mathrm{pp}$. 251-276). American Psychological Association: Washington D.C. doi: 10.1037/14641-012

Hair, J. F., Hult, G. T. M., Ringle, C. M., \& Sarstedt, M. (2017). A Primer on Partial Least Squares Structural Equation Modeling (PLS-SEM). $2^{\text {nd }}$ Ed. Thousand Oaks, CA: Sage

Jafri, H. (2013). A study of the relationship of psychological capital and students' performance. Business Perspectives and Research, 1(2), 9-16. doi: $10.1177 / 2278533720130202$

Kim, H-Y. (2013). Statistical notes for clinical researchers: Assessing normal distribution (2) using skewness and kurtosis. Restorative Dentistry and Endodontics, 38, 52-54. doi.org/10.5395/ rde.2013.38.1.52

Klein, A. G., Gerhard, C., Büchner, R. D., Diestel, S. \& Schermelleh-Engel, K. (2016). The detection of heteroscedasticity in regression models for psychological data. Psychological Test and Assessment Modeling, 58, 542-567.
Kokkinos, C. M., \& Voulgaridou, I. (2018). Motivational beliefs as mediators in the association between perceived scholastic competence, selfesteem and learning strategies among Greek secondary school students. Educational Psychology, 1-10. doi: 10.1080/01443410.2018.1456651

Liu, W. C., Wang, C. K. J., Kee, Y. H., Koh, C., San, B., Lim, C., \& Chua, L. (2014). College students' motivation and learning strategies profiles and academic achievement: A self-determination theory approach. Educational Psychology, 34(3), 338353. doi: 10.1080/01443410.2013.785067

Lopez-Agudo, L. A., \& Marcenaro-Gutierrez, O. D. (2017). Engaging children in lessons: The role of efficient and effective teachers. School Effectiveness and School Improvement, 28(4), 650-669. doi: 10.1080/09243453.2017.1364272

Lupsa, D., \& Vîrgă, D., (2018). Psychological Capital Questionnaire (PCQ): Analysis of the Romanian adaptation and validation. Psihologia Resurselor Umane [Psychology of Human Resources], 16, 27-39. doi.org/10.24837/pru.2018.1.484

Lupsa, D., Vîrgă, D., Maricutoiu, L. P., \& Rusu, A. (2019). Increasing Psychological Capital: A preregistered meta-analysis of controlled interventions. Applied Psychology. https://doi.org/10.1111/ apps. 12219

Luthans, F., Youssef, C. M., \& Avolio, B. J. (2007). Psychological Capital. Developing the Human Competitive Edge. New York, Oxford University Press.

Luthans, F., Avolio, B. J., Avey, J. B., \& Norman, S. M. (2007). Positive psychological capital: Measurement and relationship with performance and satisfaction. Personnel Psychology, 60, 541-572. doi: 10.1111/j.1744-6570.2007.00083.x

Luthans, F., \& Youssef, C. M. (2007). Emerging positive organizational behavior. Journal of Management, 33, 321-349. doi: 10.1177/ 0149206307300814

Luthans, B. C., Luthans, K. W., \& Jensen, S. M. (2012). The impact of business school students' psychological capital on academic performance. Journal of Education for Business, 87, 253-259. doi: 10.1080/08832323.2011.609844

Luthans, F., \& Avolio, B. J. (2014). Brief summary of psychological capital and introduction to the special issue. Journal of Leadership \& Organizational Studies, 21(2), 125-129. doi: 10.1177/ 1548051813518073

Moors, J. J. A. (1986). The meaning of kurtosis: Darlington reexamined. The American Statistician, 40, 283-284. doi:10.2307/2684603

Orkibi, H., \& Ronen, T. (2017). Basic psychological needs satisfaction mediates the association be- 
tween self-control skills and subjective well-being. Frontiers in Psychology, 8(936), 1-10. doi: 10.3389/fpsyg.2017.00936

Ortega-Maldonado, A., \& Salanova, M. (2017). Psychological capital and performance among undergraduate students: The role of meaning-focused coping and satisfaction. Teaching in Higher Education, 23(3), 390-402. doi: 10.1080/13562517. 2017.1391199

Panadero, E. (2017). A review of self-regulated learning: Six models and four directions for research. Frontiers in Psychology, 8(422), 1-28. doi: 10.3389/fpsyg.2017.00422.

Paris, S. J., \& Paris, A. H. (2001). Classroom applications of research on self-regulated learning. Educational Psychologist, 36, 89-101.

Pintrich, P. R., \& de Groot, E. V. (1990). Motivational and self-regulated learning components of classroom academic performance. Journal of Educational Psychology, 82(1), 33-40.

Pintrich, P. R. (2000). The role of goal orientation in self-regulated learning. In M. Boekaerts, P. Pintrich, \& M. Zeidner (Eds.), The handbook of self-regulation: Theory, research, and applications (pp. 451-502). San Diego: Academic Press.

Pintrich, P. R. (2004). A conceptual framework for assessing motivation and self-regulated learning in college students. Educational Psychology Review, 16(4), 385-407. doi: 10.1007/s10648-0040006-x

Probst, T. M., Gailey, N. J., Jiang, L., \& Bohle, S. L. (2017). Psychological capital: Buffering the longitudinal curvilinear effects of job insecurity on performance. Safety Science, 100, 74-82. doi: 10.1016/j.ssci.2017.02.002

Rahmadani, V. G., Schaufeli, W. B., Ivanova, T. Y., \& Osin, E. N. (2019). Basic psychological need satisfaction mediates the relationship between engaging leadership and work engagement: A crossnational study. Human Resource Development Quarterly,1-19. doi: 10.1002/hrdq.21366

Rotgans, J. \& Schmidt, H. (2009). Examination of the context-specific nature of self-regulated learning. Educational Studies, 35, 239-253. doi: 10.1080/ 03055690802648051

Schloemer, P., \& Brenan, K. (2006). From students to learners: Developing self-regulated learning. Journal of Education for Business, 82, 81-87. doi: 10.3200/JOEB.82.2.81-87

Schunk, D. H. (2005). Self-regulated learning: The educational legacy of Paul R. Pintrich. Educational Psychologist, 40(2), 85-94. doi: 10.1207/ s15326985ep4002 3

Sierens, E., Vansteenkiste, M., Goossens, L., Soenens, B., \& Dochy, F. (2009). The synergistic relationship of perceived autonomy support and structure in the prediction of self-regulated learning. British Journal of Educational Psychology, 79, 57-68. doi: 10.1348/000709908X304398

Siu, O. L., Bakker, A. B., \& Jiang, X. (2014). Psychological capital among university students: Relationships with study engagement and intrinsic motivation. Journal of Happiness Studies, 15, 979994. doi: 10.1007/s10902-013-9459-2

Sulea, C., van Beek, I., Sârbescu, P., Vîrga, D., \& Schaufeli, W. B. (2015). Engagement, boredom, and burnout among students: Basic need satisfaction matters more than personality traits. Learning and Individual Differences, 42, 132-138. doi: 10.1016/j.lindif.2015.08.018

Tânculescu, L., \& Iliescu, D. (2014). Adaptarea culturală a scalei Satisfacerea nevoilor psihologice la locul de muncă în context românesc [Cultural adaptation of the Work-related Basic Need Satisfaction against the Romanian background]. Psihologia Resurselor Umane [Psychology of Human Resources], 12, 130-146.

Valero-Valenzuela, A., \& Manzano-Sánchez, D. (2019). Interpersonal style of coaching, motivational profiles and the intention to be physically active in young athletes. Studia Psychologica, 61(2), 110-119. doi: 10.21909/sp.2019.02. 776

van den Broeck, A., Vansteenkiste, M., De Witte, H., \& Lens, W. (2008). Explaining the relationships between job characteristics, burnout, and engagement: The role of basic psychological need satisfaction. Work \& Stress: An International Journal of Work, Health \& Organizations, 22(3), 277-294. doi: 10.1080/02678370802393672

van den Broeck, A., Vansteenkiste, M., De Witte, H., Soenens, B., \& Lens, W. (2010). Capturing autonomy, competence, and relatedness at work: Construction and initial validation of the work-related basic need satisfaction scale. Journal of Occupational and Organizational Psychology, 83, 981-1002. doi: 10.1348/096317909X481382

van Veldhoven, M., \& Meijman, T. F. (1994). Het meten van psychosociale arbeidsbelasting met een vragenlijst: De vragenlijst beleving en beoordeling van de arbeid (VBBA). [The measurement of psychosocial job demands with a questionnaire: The questionnaire on the experience and evaluation of work (QEEW)]. Amsterdam: NIA

Verleysen, B., Lambrechts, F., \& Acker, F. V. (2015). Building psychological capital with appreciative inquiry: Investigating the mediating role of basic psychological need satisfaction. The Journal of Applied Behavioral Science, 51(1), 10-35. doi: 10.1177/0021886314540209 
Vîrga, D., De Witte, H., \& Cifre, E. (2017). The role of perceived employability, core self-evaluations, and job resources on health and turnover intentions. The Journal of Psychology, 151(7), 632-645. doi: 10.1080/00223980.2017.1372346

Wernsing, T. (2014). Psychological capital: A test of measurement invariance across 12 national cultures. Journal of Leadership \& Organizational Studies, 21(2), 179-190. doi: 10.1177/ 1548051813515924

Zimmerman, B. J. (1990). Self-regulated learning and academic achievement: An overview. Educational Psychologist, 25(1), 3-17.

Zimmerman, B. J. (1998). Academic studying and the development of personal skill: A self-regulatory perspective. Educational Psychologist, 33(23), 73-86.

Zhu, J., \& Mok, M. M. C. (2018): Predicting primary students' self-regulated learning by their prior achievement, interest, personal best goal orientation and teacher feedback. Educational Psychol- ogy, 38(9), 1106-1128. doi: 10.1080/01443410. 2018.1497775

Zusho, A. (2017). Toward an integrated model of student learning in the college classroom. Educational Psychology Review, 29, 301-324. doi: 10.1007/s 10648-017-9408-4

You, J. W., Kim, B., \& Kang, M. (2014). The effects of psychological capital on self-directed learning and learning engagement for college students. Journal of Learner-Centered Curriculum and Instruction, 14(3), 45-70.

You, J. W. (2016). The relationship among college students' psychological capital, learning empowerment, and engagement. Learning and Individual Differences, 49, 17-24. doi: 10.1016/j.lindif. 2016.05.001

Young, M. R. (2005). The motivational effects of the classroom environment in facilitating self-regulated learning. Journal of Marketing Education, 27(1), 25-40. doi: $10.1177 / 0273475304273346$ 